\title{
Investigating Attitudes of Prospective Mathematics Teachers towards the Use of Mobile Learning at a Higher Learning Institution ${ }^{\mathrm{i}}$
}

\author{
Halil Coşkun Çelik ${ }^{1, *}$, Saffet Karayaman $^{2}$ \\ ${ }^{1}$ Mathematics and Science Education Department, Faculty of Education, Siirt University, Turkey \\ ${ }^{2}$ Ministry of National Education, Istanbul National Education Directorate, School Director, İstanbul, Turkey
}

Copyright $(2018$ by authors, all rights reserved. Authors agree that this article remains permanently open access under the terms of the Creative Commons Attribution License 4.0 International License

\begin{abstract}
The aim of this study is to investigate the attitudes of prospective mathematics teachers towards mobile learning based on different variables and examine their opinions on this subject. This study used an exploratory design, which is a mixed design involving the analysis of qualitative and quantitative data collected together. The participants, which consisted of 181 prospective teachers, were selected by convenient sampling. The study was performed with a mixed method in which both qualitative and quantitative data were collected and analyzed together. The quantitative data of this study were collected by a mobile learning attitude scale, while the qualitative data were collected via a structured interview form. Independent samples t-test was used to analyze the quantitative data, while content analysis was used on the qualitative data. As a result of the study, it was found that the attitudes of the prospective teachers towards mobile learning were on a medium-level both in the general total and sub-factor (freedom, advantages, practicality and limitations) scores, and the attitudes of the male participants were higher than those of the female participants. On the other hand, it was found that the prospective mathematics teachers had positive views on mobile learning, most stated that this type of learning has advantages and disadvantages and it may be used in extracurricular environments and increases course success, but it is not economical.
\end{abstract}

Keywords Attitude, Gender, Mathematics Education, Mobile Learning, Prospective Mathematics Teachers

\section{Introduction}

Very fast development of mobile technologies introduced the concept of being "mobile=moving" into our lives, and with the help of mobile technologies that have been developed since the 2000s, mobile learning emerged as a new concept in education [7]. The concept of "mobile" which became prevalent with communication technologies is used along with meanings of wireless communication, mobility and portability. A fundamental principle of mobile learning depends on the mobility of learners. It is an active process of establishing knowledge through practice, and embracing learning that occurs within informal settings such as work [52]. Education activities carried out with mobile communication devices are called mobile learning [26]. Mobile learning is not only learning that is based on the use mobile devices but also learning that is mediated across multiple contexts using portable mobile devices [40]. Mobile learning is a "new paradigm" that ensures another form of electronic learning [38]. Mobile learning complements a constructivist, learner-centered approach because it is personal, socially networked, and contextual with the locus of control residing with the learner [27]. Mobile learning does not consist only of activities with learning purposes, but it also covers practices that were not particularly designed for learning but may be used for learning. The advantage of 24/7 mobility and access to cellular/wireless network connections provided by mobile devices supports life-long learning by individuals. The individual is able to access different environments in various segments of life without spending additional effort, and therefore, mobile learning leads to the emergence of a new learning mobility [63]. Mobile learning has some benefits such as learning new things while on the move, using time effectively and efficiently while waiting, and answering questions fast [26]. With the help of mobile devices, students can access the much-needed educational information related to their learning, both from within the classroom and outside the classroom [42].

Mobile learning is a popular research area that attracts many researchers to investigate this learning strategy, study its impacts on students and educators, and develop 
the required infrastructure [4, 21, 34]. Mobile learning is also called m-learning. Mobile learning was derived from the rapid development in mobile devices, computer technologies, wireless technologies, and it became one of the items in the agenda of the field of education and instruction. Park [47], Aderinoye, Ojokheta, and Olojede [1] defined mobile learning as the use of mobile or wireless devices for the aim of learning while on the move. Also, with the use of mobile devices, learners can learn anywhere and at any time. On the other hand, Traxler [58] defined mobile learning as wireless and digital devices and technologies, usually produced for the public, used by a learner as he or she participates in higher education. Mobile learning complements a constructivist, learner-centered approach because it is personal, socially networked, and contextual with the locus of control residing with the learner [27].

Attitude is a key variable that affects using mobile learning in educational environment. Attitude is a way of preliminary thinking that includes emotions and beliefs regarding an individual's assumptions about the world, expectations from other people, values and viewpoints, and what they need to approach or avoid [35]. In other words, attitude is a complex mental state involving beliefs and feelings [22]. Attitudes are gained through time and they are hard to change. Attitudes are related to the advantages of mobile learning, limitations, practicality and freedom [13]. Considering that attitude is a strong predictor of intent based on previous studies, attitude is an important factor in revealing intent towards usage of mobile learning [28].

Mobile technologies are considered to be no exception due to their numerous instructional features and ability to supply access to learning anywhere. Due to the increased ubiquity and instructional features of mobile technologies, mobile learning has become "one of the key current trends of educational applications for new technologies. Mobile technologies in our learning environments are nowadays seen widely as increasingly ubiquitous in the society, particularly with youth [53]. Through the appropriate use of technologies in a math classroom, students can learn more effectively, and learning of students is enhanced on a deeper level [49, 61]. Mobile learning has acquired popularity among students and educators for performing daily tasks in a more flexible and comfortable style. Diverse universities worldwide enforced mobile learning for delivering learning anytime and anywhere in different ways [4]. On the other hand, the subject of the relationship between gender differences and mobile learning has been an important matter within the discussion on educational technology in higher education campuses. In a broader context, gender is considered a principle, to clarify the inequalities and identities in our society [39]. It is stated that gender differences in the learners' perceptions toward educational technology should be considered in developing, delivering, and applying educational technology [30]. In the background of computer technologies, the literature recognizes that gender is an element for understanding the differences in user perceptions and attitudes toward technology adoption; especially for learning purposes [39]. For this reason, understanding how gender differences effect the learning adoption is a serious matter on a mobile learning attitude. Additionally, with the rapid advancement of technology, students of many universities in the last decade are taking Turkish Language, History of Atatürk's Principles and Reforms and English Language courses via distant education in synchronous and asynchronous ways. Students are able to access the distant education system via tablets, smartphones and desktop computers whenever and wherever they want. Students who are receiving education in this context are able to utilize the advantages mobile learning to a great extent. This way, they may reach information about general status of the courses they take, their grade points, assignments, attendance records, registration processes, announcements and various documents they may need (student certificate, excuse forms, examination retake forms, etc.) using mobile devices.

Prospective teachers are needed to not only demonstrate advanced skills of technology usage, but also use these technologies on optimal levels of efficiency in teaching-learning processes [25]. By the means of classes that prioritize improving usage of developed information technologies and various materials required for instruction, it was aimed for prospective teachers to recognize and utilize various technologies such as computers, the internet, multimedia, television, video and projectors. This way, teachers of the future were projected to have the quality to know about technology and utilize it in instruction in an effective and efficient way The Council of Higher Education [59]. Technology usage has rapidly improved from the past to the present in the field of mathematics instruction, too. It may be argued that this is one of the top areas of education where education technologies are adopted and utilized the fastest. This is because national and international organizations and institutions encourage the usage of technology [46]. The National Council of Teachers of Mathematics [44] defended the idea that technology is crucial in learning and teaching mathematics; it influences learning mathematics and increases students' learning. Technology is a tool that should enhance student learning and achievement. The results of studies showed that technology has a positive effect on students' math achievements [20,43] or that technology has no impact on student achievements [45].

The national and international literatures in the last decade include various studies conducted on mobile learning. In a content analysis study, it was reported that postgraduate dissertations prepared in Turkey between 2005 and 2015 investigated the effects of mobile learning on academic success most frequently, this topic was followed by attitudes towards mobile learning, and these studies mostly worked with university students as their sample [54]. For example, in a study conducted for measuring the attitudes and perceptions of students on the 
effectiveness of mobile learning, it was demonstrated that mobile learning would be a suitable method for students on undergraduate and postgraduate levels [5]. In some studies, it was reported that university students had positive perceptions on mobile learning, they adopted this type of learning, it was an effective method of learning, and they wanted to use it in their classes [36, 63]. A study with Korean university students showed that one of the most important factors that predicted mobile learning by students was the attitude towards mobile learning [48]. On the other hand, some studies stated that mobile learning may have potential negative effects based on wrong designs of learning or lack of sufficient support for learning $[15,55]$ and the perception levels of university students were low towards mobile learning [57].

Mobile learning has become an important educational technology component in higher education [4]. This learning, which has the potential to become one of the effective methods towards higher education in the future, is an approach whose contribution is increasingly higher in instruction-learning processes that are adopted more frequently than traditional instruction methods and will inevitable be integrated in educational settings. Therefore, it is seen as a significant necessity to determine the attitudes of prospective teachers towards mobile learning and discuss their opinions on this matter in detail. This way, it is possible to determine whether prospective teachers adopted mobile learning or not, whether they are ready to use it or not, and their strong and weak aspects regarding mobile learning. In this context, the general purpose of our study is to investigate the attitudes of prospective mathematics teachers towards mobile learning and learn about their opinions on this matter. Therefore, our research seeks to answer the following research questions:

1. What is the level of prospective mathematics teachers' attitudes towards mobile learning?

2. Is there any significant difference among prospective mathematics teachers' attitudes towards mobile learning in terms of gender?

3. Is there any significant difference among prospective mathematics teachers' attitudes towards mobile learning based on ownership of a tablet computer?

4. What are the views of prospective mathematics teachers on mobile learning? Do these views differ based on different variables?

\section{Method}

\section{Research Design}

The study used an exploratory design, which is a mixed design involving the analysis of qualitative and quantitative data collected together. Mixed methods combine quantitative and qualitative research methods in a study that has one or more stages. They allow better understanding of the research question than in the case of a single method design [8]. This study employed a mixed method due to the expectation that understanding, answering and reporting the results of the research question would have shortcomings if a single qualitative or quantitative method was used by itself. In explanatory design, quantitative data are collected and analyzed; then, qualitative data are collected and analyzed for quantitative data to be complemented and refined [11]. As this study collected both quantitative and qualitative data, an explanatory mixed design is a suitable research method to investigate the attitudes of prospective mathematics teachers and collect their views on this matter.

\section{Participants}

The participants of the study consisted of 181 prospective mathematics teachers selected by convenient sampling who were enrolled at the department of mathematics and science education and instruction at the faculty of education of a state university located in the Southeastern Anatolia Region in Turkey during the academic year of 2016-2017. Among the 181 participants, 117 were female and 64 were male, and their ages differed in the range of 18-26. Convenient sampling method; time, money, and the available frequencies for the workforce are easily accessible and united [11]. In addition, ordered quantitative-qualitative technique is the most widely used technique in the literature. In many studies carried out with this technique, the last sample used in the quantitative step is used as a determinant for selecting the sample in the later qualitative step [32]. After the sample determined in the quantitative stage was determined, the sub-sample for the qualitative stage was formed by the convenient sampling method and Structured Interview Form was applied to 20 people.

\section{Data Collection Tools}

In the study was used a mobile learning attitude scale to collect quantitative data, and a structured interview form to collect qualitative data.

The Mobile Learning Attitude Scale: This was developed by Çelik [13] with the purpose of determining the attitudes of university students towards mobile learning. The scale consists of a 5-point Likert-type format, and 21 items including 16 positive and 5 negative ones. The variance explained by the four factors in the scale (advantages, limitations, practicality and freedom) is $51.6 \%$. The Cronbach's Alpha reliability coefficient of the scale used in this study was calculated as 0.80 . This value shows that the scale is reliable [31]. The items on the scale were coded as 1 for "absolutely disagree", 2 for "disagree", 3 for "undecided", 4 for "agree" and 5 for "absolutely agree". The maximum score that may be obtained from the scale is 105 , while the minimum is 21 .

The Structured Interview Form: This form was 
developed by the researchers following the comprehensive literature review with the purpose of recording the opinions of the participants regarding mobile learning. The form contains questions that allow participants to openly express their opinions on mobile learning. Expert opinions were sought with the aim of confirming the adequacy of these questions by consulting three people who are experts in their fields (measurement-assessment, computer education, mathematics education). Necessary adjustments were made in line with the feedbacks, and the form consisting of 7 open-ended questions took its final form. The questions in the form are related to the effects of mobile learning on academic success, its psychological, pedagogic and technical limitations, its economic dimension, and basic skills and talents students should hold in a mobile learning environment. In order to calculate the reliability to form, Structured Interview Form questions were evaluated by field experts and scored by two field education specialists. In order to evaluate the reliability between the scorers, the Kappa (Inter-Scorer Cohesion) coefficient was calculated. The value calculated for the required evaluations is 0.86 ([Kappa] $>0.75$ ), which is the result of compliance.

After the sample was identified in the study, the mobile learning attitude scale and the interview form were applied to prospective mathematics teachers, respectively. The applications were made by the relevant researchers with necessary explanations. For the scale and interview form, the mathematics teacher candidates were given one hour to complete the process.

\section{Data Analysis}

The analysis of the data was followed in two parts, due to consideration of the qualitative and quantitative dimensions of the study. The data collected for the quantitative dimension of the study were analyzed using the SPSS 21.0 package software, and the study utilized descriptive statistics, t-test and one-way analysis of variance techniques. In order to make the interpretation of the obtained scores easier, the total score obtained from the mobile learning attitude scale was divided by the total number of items, and the scores of the sub-scales were divided into the number of items in the sub-scales, and the results were therefore converted into averages in the range of 1-5. The mobile learning attitude levels of the participants were classified as low attitude, medium attitude and high attitude levels by considering the mean score obtained in the scale, standard deviation, and minimum and maximum scores that can be obtained from the scale. As the mobile learning attitude scores were calculated based on a 5-point Likert-type scale, the expected score range was 1.00-5.00. Accordingly, the levels of mobile learning attitudes were determined as low in the range of 1.00-2.33, as medium in the range of 2.34-3.67, and high in the range of 3.68-5.00. In the qualitative dimension of the study, structured interviews were conducted with the aim of learning about the opinions of 13 prospective teachers on mobile learning, and the data collected from the interviews were included in content analysis. One of the most frequently used methods in the analysis of qualitative data is content analysis. This method aims to make systematic and objective inferences on data (generally text) and impartially determine the particular characteristics (classes or categories) of the data [23]. The data that were coded and organized beforehand for content analysis was coded into an MS Excel sheet and reviewed to reach a general overview. For each open-ended question in the form, the data were divided into meaningful sections and it was aimed to make sense of them conceptually. The sections that constituted meaningful wholes within themselves were coded, similarities and differences between the codes were examined, and a theme name was assigned to the codes related to each other. The interrelations of the codes in the themes were then interpreted by explanation, and causality relationships were investigated with the help of the literature and direct quotes.

\section{Results}

\section{Results on the Quantitative Dimension of the Study}

The study investigated the general distribution of the attitudes of prospective teachers towards mobile learning and sub-factors (advantages, limitations, practicality and freedom) of these attitudes. Additionally, quantitative findings were examined for the comparison of the attitudes towards mobile learning and their sub-factors in terms of gender and ownership of a tablet computer.

The descriptive statistics and attitude levels regarding the mobile learning attitudes of the prospective teachers and sub-factors are given in Table 1.

Table 1. General distribution of mobile learning attitudes and sub-factors

\begin{tabular}{lccccccc}
\hline Factors & $\mathrm{N}$ & Min & Max & Skewness & Kurtosis & $\overline{\mathrm{X}} \mathrm{S}$ & Attitude Level \\
\hline Advantages & 181 & 1 & 5 & 0.62 & 0.59 & $3.41 \mp 0.72$ & Medium \\
Limitations & 181 & 1 & 5 & 0.04 & 0.10 & $3.06 \mp 0.72$ & Medium \\
Practicality & 181 & 1 & 5 & 0.45 & 0.34 & $3.23 \mp 0.85$ & Medium \\
Freedom & 181 & 1 & 5 & 0.72 & 0.34 & $3.46 \mp 0.78$ & Medium \\
General Total & 181 & 1 & 5 & 0.66 & 0.52 & $3.29 \mp 0.52$ & Medium \\
\hline
\end{tabular}


According to Table 1, the mean general attitude score of the prospective teachers was 3.29 with a standard deviation of 0.52 . On the other hand, the mean values of the sub-factors of the scale were found in, from the highest to the lowest, freedom (3.46), advantages (3.41), practicality (3.23) and limitation (3.06). Additionally, the attitudes of the prospective teachers were on a medium level in both the general total of the scale and its sub-factors (freedom, advantages, practicality and limitations).

The study used independent-samples t-test to determine whether the mobile learning attitudes and sub-factors of the prospective teachers differed based on gender. Table 2 shows the findings regarding the analysis

Table 2. t-test results for mobile learning attitudes based on gender

\begin{tabular}{|c|c|c|c|c|c|c|}
\hline Factors & Gender & $\mathrm{N}$ & $\overline{\mathrm{X}}$ & S.S. & sd & t. \\
\hline \multirow{2}{*}{ Advantages } & Female & 117 & 3.42 & 0.68 & \multirow{2}{*}{179} & \multirow{2}{*}{0.30} \\
\hline & Male & 64 & 3.38 & 0.80 & & \\
\hline \multirow{2}{*}{ Limitations } & Female & 117 & 2.97 & 0.68 & \multirow{2}{*}{179} & \multirow{2}{*}{$2.33^{*}$} \\
\hline & Male & 64 & 3.23 & 0.75 & & \\
\hline \multirow{2}{*}{ Practicality } & Female & 117 & 3.25 & 0.80 & \multirow{2}{*}{179} & \multirow{2}{*}{0.44} \\
\hline & Male & 64 & 3.20 & 0.94 & & \\
\hline \multirow{2}{*}{ Freedom } & Female & 117 & 3.51 & 0.71 & \multirow{2}{*}{179} & \multirow{2}{*}{1.03} \\
\hline & Male & 64 & 3.38 & 0.89 & & \\
\hline \multirow{2}{*}{ Total } & Female & 117 & 3.29 & 0.48 & \multirow{2}{*}{179} & \multirow{2}{*}{0.14} \\
\hline & Male & 64 & 3.30 & 0.60 & & \\
\hline
\end{tabular}

Table 2 shows that male prospective teachers generally had higher mean scores of mobile learning attitudes (3.30) than female prospective teachers (3.29), while this difference was not significant. It was also found that the mean scores of the male prospective teachers in the sub-factors of advantages (3.42), practicality (3.25) and freedom (3.51) were higher than their mean score in the limitations sub-factor (3.23), while the difference was not significant.

Independent samples t-test was used to determine whether mobile learning attitudes and sub-factors of the prospective teachers differed based on their ownership of a tablet computer. The findings are presented in Table 3 .

Table 3. t-test results for mobile learning attitudes based on ownership of a tablet computer

\begin{tabular}{lcccccc}
\hline Factor & $\begin{array}{c}\text { Tablet } \\
\text { Ownership }\end{array}$ & $\mathrm{N}$ & $\overline{\mathrm{X}}$ & S.S. & sd & $\mathrm{t}$. \\
\hline \multirow{2}{*}{ Advantage } & Yes & 54 & 3.44 & 0.82 & & \\
& No & 127 & 3.39 & 0.67 & 179 & 0.41 \\
Limitations & Yes & 54 & 2.93 & 0.68 & & \\
& No & 127 & 3.12 & 0.73 & & \\
Practicality & Yes & 54 & 3.35 & 0.92 & & \\
& No & 127 & 3.19 & 0.82 & & \\
Freedom & Yes & 54 & 3.50 & 0.88 & & \\
& No & 127 & 3.45 & 0.73 & & 0.45 \\
Total & Yes & 54 & 3.31 & 0.59 & & \\
& No & 127 & 3.29 & 0.49 & & 0.25 \\
\hline
\end{tabular}

According to Table 3, in general, the prospective teachers who did not have tablet computers had a lower mean score (3.29) than those who had tablet computers (3.31), but the difference was not significant. Additionally, the mean scores of the prospective teachers who had tablet computers were higher than those without tablet computers in the sub-factors of advantages (3.34), practicality (3.35) and freedom (3.50). However, their mean score in the sub-factor of limitations (2.93) was found lower than that of the participants without tablet computers (3.12).

\section{Results on the Qualitative Dimension of the Study}

The data in the qualitative dimension of the study were collected by the application of the structured interview form with the aim of learning about their opinions and thoughts on mobile learning in detail. General tendencies in the responses of the prospective teachers were presented in a descriptive way. The names of the prospective teachers were replaced with $\mathrm{T} 1, \mathrm{~T} 2, \ldots, \mathrm{T} 13$ to be in compliance with scientific ethics rules.

20 prospective teachers responded to the question "what are your opinions on the advantages and disadvantages provided to the students by usage of mobile devices in the classroom?" As a response to this question, $23.1 \%$ of the participants thought mobile learning provided advantages, $15.4 \%$ thought it provided disadvantages, and $61.5 \%$ thought it provided both advantages and disadvantages. The opinions of some of the prospective teachers who responded to this question were as the following;

T2: "I think it is beneficial in terms of materials and videos suitable for the course of the class, but it makes the student lazier."

T4: "It is advantageous in terms of practicality. It is disadvantageous as it is distracting."

T5: "It is advantageous as it increases the motivation of the student for the class."

T16: "They would not listen to the class. There is addiction for the mobile learning device."

Based on these opinions of the prospective teachers, it may be suggested that usage of mobile devices in the classroom has both advantages and disadvantages, but it is more advantageous to use mobile learning devices in mathematics classes.

13 prospective teachers responded to the question "what are your feelings and thoughts about the practicality of mobile devices for learning environments?" $76.9 \%$ of the participants thought they are practical, $15.4 \%$ thought they are impractical, and $7.7 \%$ thought they are practical in some cases while being impractical in others. The opinions of some of the prospective teachers were as the following:

T4: "They are very fine tools to reach substantial amounts of information. I think they are beneficial for learning." 
T15: "They are practical because one can reach information very quickly. They are very suitable for classroom usage."

T6: "They are practical and modern. They provide practicality."

The opinions provided above suggest that most of the prospective teachers thought mobile devices are practical instructional tools in learning environments.

12 prospective teachers responded to the question "what are your thoughts about the economic dimensions of mobile learning?" and one person did not respond. $23.1 \%$ of the participants stated that mobile learning is economical, $46.2 \%$ said it is not economical, $15.4 \%$ said it is economical in terms of time, and $7.7 \%$ said it is economical in terms of money. Some of the opinions on the economic dimension of mobile learning were as the following:

T1: "It is not economical in terms of money, but it is economical in terms of time."

T3: "It saves time. Mobile devices have high cost. They are expensive in the economic sense."

T14: "It has economic limitations. This is because not every student has technological devices."

These comments may suggest that the prospective teachers thought mobile learning is not economical due to the costs of mobile devices.

11 prospective teachers responded to the question "what are your thoughts about usage of mobile devices for learning purposes outside the classroom?" and 2 people did not respond. $69.2 \%$ of the participants stated that mobile learning may be used in extracurricular settings, while $15.4 \%$ said it may not. Some examples of the opinions of the prospective teachers were as the following:

T5: "For example, I follow the classes I miss on YouTube. Therefore, it provides alternative learning."

T13: "As it is used outside the classroom, it provides the opportunity to repeat the parts that are not understood in the classroom."

T9: "I think usage of mobile devices in our daily lives is easy and good."

These comments suggest that the prospective teachers thought learning activities may be carried out outside the classroom with the prevalence and popularity of mobile devices in our lives.

12 prospective teachers responded to the question "what would you like to say about the basic skills and talents (e.g. studying individually, individual desire to learn, attention, motivation and research skills) mobile learners should have?" and 1 person did not respond. 84.6\% of the prospective teachers stated that learners in a mobile learning environment should have basic skills and talents, while $7.7 \%$ said there is no such necessity. Some opinions regarding this issue are given below.
T2: "If the student likes to follow classes on a tablet and learns better, it is very useful. Every student has different ways of learning."

T4: "Mobile learners must definitely have an individual desire to learn."

T5: "Mobile learners should have high motivation and no interest in other things (such as games, etc.)."

These suggest that the prospective teachers thought mobile learners should have characteristics such as individual studying, individual desire to learn, and attention, motivation and research skills.

13 prospective teachers responded to the question "what sort of relationship do you think exists between mobile learning and academic success?" $53.8 \%$ of the participants stated that there is a positive relationship between mobile learning and academic success, 30.8\% said there is a negative relationship, and $15.4 \%$ stated that there is no relationship.

T5: "In my opinion, mobile learning and academic success are inversely proportionate. It is easier to get lost in external factors with mobile learning; therefore, it reduces academic success."

T6: "It becomes useful in the correct way and in compliance with its purpose."

T13: "It increases academic success."

According to these results, most of the prospective teachers thought that mobile learning increases academic success.

Finally, 8 prospective teachers responded to the question "what are your opinions on the psychological, pedagogic and technical limitations that pose a problem in mobile learning?" and 5 people did not respond.

T16: "Phone addiction should be minimized. Phones should be allowed only for a certain time." T19: "It is harmful in terms of addiction to mobile devices."

T5: "A person should use mobile devices in compliance with its purpose when they will learn from them."

$46.2 \%$ of the participants who responded stated that mobile learning has psychological, pedagogic and technical limitations, while $15.4 \%$ did not see these issues as limitations.

\section{Conclusion, Discussion and Recommendations}

Mobile learning is one of the popular instruction approaches of the 21 st century, and it is increasingly becoming inevitable that it will be integrated into educational settings. Therefore, it is needed that prospective teachers gain awareness regarding mobile learning, their attitude and behavior dimensions are revealed, and their opinions are collected on this issue. This 
study presented the general attitudes of prospective mathematics teachers towards mobile learning, and their attitudes towards the sub-factors of advantages, limitations, practicality and freedom of this type of learning. Additionally, the changes in the mobile learning attitudes and sub-factors based on gender and ownership of a tablet computer were investigated, and then, the participants' opinions on the issue were collected. In this context, the prospective mathematics teachers were given the mobile learning attitude scale and the structured interview form. The quantitative and qualitative data were analyzed.

Recently, some studies in the field of mobile learning indicated that the attitudes of students towards mobile learning are high $[19,24,37]$ while others indicated low levels [57]. Mobile learning is a new educational tool. This study found that the mobile learning attitudes of the prospective teachers were on a medium level both in terms of the general total and the sub-factors (freedom, advantages, practicality and limitations). This may have been caused by the prospective teachers not seeing themselves adequate in terms of techno-pedagogic and practical richness of knowledge on integration of mobile learning into learning environments. Besides, the medium-level attitudes of the participants in the study may be explained by their lack of usage of mobile learning in classes for education purposes, their preference of using mobile devices for entertainment and connection to social networks and their lack of experience in this matter. This result supports the results of studies in the literature that showed that the mobile learning attitudes of prospective teachers are on a medium level $[29,63]$. Additionally, studies showed that most of the university students embraced usage of mobile devices in education and training processes $[5,18,39$, and 63$]$ and therefore mobile learning, and found it important and useful.

Mobile learning brought improvement and numerous changes to the educational environment and impressed all its parts. In this study, it was found that the attitudes of the prospective teachers towards the mean value of the sub-factor of "freedom" were higher than those towards the sub-factors of "advantages", "practicality" and "limitations". In mobile learning, students' ability to start the learning process independently of time and place and join the process and interfere with it whenever they want, is important in terms of freedom. Moreover, mobile learning has opportunities to repeat the classes students missed or could not follow, and it provides possibility of quick feedback. Using mobile technology for educational purposes such as content delivery, sharing information and files, communication and collaboration has been evident and it has demonstrated tremendous benefits for students and instructors. Mobile technology, in general, has altered our pace of life in terms of receiving and distributing information, social and educational communication, interaction and many other aspects [3]. Additionally, mobile technology utilizes modern tools such as tablet computers, laptops and smartphones to support learning. Colazzo et al. [16] stated that learning and teaching activities are possible in a mobile learning environment with appropriate and correct mobile devices or settings. In addition to this, ease of carrying mobile tools, access to information and features that allow easy access and personalization may create "advantages" and "practicality" for the concept of "freedom" in mobile learning. The finding in our study that the levels of attitudes were medium in the sub-factors of "freedom", "advantages" and "practicality" may be related to these issues. The findings in the literature agree with our results. For example, Al-Emran et al. [4] revealed significant differences among university students' attitudes in terms of their smartphone ownership where the differences were in favor of both devices (smartphone and tablet), i.e. student "learners" who had both devices and familiarity with mobile technology were more positive towards the use of such technology in learning than the others. Furthermore, Ağca and Bağc1 [2] indicated that the unique qualities of mobile tools such as accessibility, personalization and portability are important contributors to learning activities.

It may be argued that the mobile learning attitudes of prospective teachers are on a medium level because mobile learning is not prevalent, there is lack of easy access to mobile technologies, mobile learning cannot be completely integrated into the curriculum, and prospective teachers do not see themselves as adequate in terms of techno-pedagogic field skills in adopting mobile learning in learning environments. Furthermore, limitations of mobile learning include the fact that not every student owns some technological tools that are integrated with mobile learning (tablet, smartphone, laptop, etc.), low skills of students in using these or high cost requirements, as well as that they do not have access to suitable software. The finding in the study that the "limitations" sub-factor had a medium-level attitude may be explained by this issue, in addition to the opinions of students that they can overcome these limitations despite the potential problems mentioned above. There are very few studies that showed obstacles with negative views on mobile learning. For example. Alfarani [6] stated that mobile learning has the potential to improve collaboration among students. However, she recorded some obstacles (resistance to change, social culture) which had negative effects on mobile learning acceptance. In another study by Çuhadar [17] on prospective teachers, it was stated that integration of tablet computers into educational settings is affected negatively by lack of hardware and software. Additionally, Ağca and Bağc1 [2] reported that motivation of students is lowered due to issues such as slow performance of some mobile tools in mobile learning environments, and limited or non-existent internet access. The reasons in question may lead to limitations for mobile learning. These may have played a role in our study's finding that the attitude toward the "limitations" sub-factor was medium-level. 
Results of studies on the effects of gender on mobile learning vary. Difference in gender is an important factor that should be accounted for in mobile learning environments. In other words, it is rational to argue that male and female students have different perceptions towards mobile learning environments [39]. An important finding of this study was that the mobile learning attitudes of the male students were higher than those of the female students, but the difference was not significant. This result agrees with those of other studies in the literature $[36,39$, $63,62]$, while some other studies reported the opposite [4, 33]. On the other hand, again in this study, it was found that the attitudes of male students towards the advantages, practicality and freedom sub-factors of the scale were higher than those towards the limitations sub-factor, but not significantly higher. This may be explained by that the skills of female prospective teachers towards taking notes, studying in a planned and systematic way and their interest towards mobile learning were higher than their male counterparts.

It is impossible to think that mobile learning will be achieved without using technological tools. In addition to mobile phones, notebook and desktop computers, tablet computers are also tools that are indispensable in mobile learning. This study reached the conclusion that the prospective teachers who had tablet computers had higher mobile learning attitude scores than those who did not have tablet computers. Prevalence of mobile learning environments is dependent on adoption of relevant technologies by students who will receive education in these environments [41] and their ability to use these technologies. These results of the study may have been caused by the participants who had tablet computers using mobile devices, having more experience in mobile learning and adopting these technologies. It may be argued that tablet computers' characteristics such as easy portability and independence from location were effective on the result that the attitudes of the prospective teachers towards the advantages, practicality and freedom sub-factors of mobile learning were higher. Integration of technological tools and devices such as tablet computers, smartphones and interactive boards into learning environments, increasing the number of users of these and sufficiency of the techno-pedagogic field on this issue may play a significant role in development of positive attitudes in prospective teachers. Preparation of mobile learning environments for prospective teachers and provision of computer usage opportunities lead to increases in their knowledge and skills of tablet computer usage [26]. In this study, the attitudes of the prospective teachers who had tablet computers were found higher in the sub-factors of advantages, practicality and freedom in comparison to those who did not have tablet computers. On the other hand, their attitudes towards the limitations sub-factor were lower in comparison to those who did not have tablet computers. Aydemir, Küçük and Karaman [9] reported that tablet computers make the distant education process easier, and applications increase the elasticity of time and location. Nevertheless, it was reported that utilization of the advantages of mobile learning to an advanced extent cannot be possible only by having the skills to use a portable device [60].

Studies in the literature that investigated opinions towards mobile learning showed that prospective teachers have positive opinions on mobile learning [12, 56, 63]. Similarly, in another study, most of the students thought that usage of mobile learning in the process of instruction and learning is necessary, and mobile learning is important and useful [18]. This study found that prospective teachers supported the idea that usage of mobile devices in the classroom is advantageous and practical in learning environments. The reason for this result may be that mobile devices appeal to more than one sense and they increase students' motivation as they attract them. This opinion of the participants may be explained by developing technological opportunities, as well as possibility of implementing mobile technologies anywhere and anytime. In their study, Ağca and Bağcı [2] reached the conclusion that mobile devices help learners reach information in the fastest and most effective way. Likewise, Saran, Seferoğlu and Cagiltay [51] reported in interviews with students that education-oriented usage of the interactivity and portability characteristics of mobile phones created advantages for students. Similarly, Rismark et al. [50] stated that the opportunity to reach mobile devices on demand has advantages. In the study by Özgen and Bindak [46], a large majority of the students stated that tools such as boards, books made the process of learning mathematics easier, but positive opinions on tools such as computers, projectors, calculators were less frequent.

Furthermore, in this study, it was found that prospective teachers thought mobile learning may be used outside the classroom for education purposes and it increases academic success. This result supports the quantitative findings. Bozkurt [10] reported that learners may be provided support services with mobile devices and applications; there is an opportunity to access learning materials via digital books or networks; the process of learning, learning resources, and opportunities and experiences of learning are enriched this way, and opportunities are provided for the act of learning to continue without interruptions. This agrees with the findings of this study on the reasons of prospective teachers for using mobile learning, which provides opportunity to access information fast and easily, in educational activities, and reasons for their opinion that it increases academic success. Likewise, in this study, it was stated by the participants that mobile learners should have basic skills and talents such as studying individually, individual desire to learn, attention, motivation and research skills. Again, the participants thought that mobile learning increases academic success despite the psychological, pedagogic and 
technical limitations that pose problems in mobile learning. Çelik [14] observed that students were sidetracked, and they lost their motivation for the class because some mobile devices were slow and there were occasional issues such as not being able to connect to the wireless network. In the same study, it was reported that mobile device usage raised curiosity in users despite these problems, motivated them positively in the process of learning words, and helped make the class more interesting.

It is considered that mobile learning attitudes of students are affected by various factors such as smartphones, desktop computers, tablet computer and laptop ownership, gender, internet access, experience in and purpose of mobile technology usage and academic success. The limitations of this study include the consideration of gender and tablet computer ownership only, among other factors. Additionally, the study included prospective mathematics teachers that were enrolled in one university, and their mobile learning attitudes and related opinions were collected using an attitude scale and an interview form. Researchers who will conduct a study on mobile learning attitudes may be recommended to additionally include prospective mathematics teachers of other universities, and prospective teachers from other disciplines. Moreover, it may be recommended that researchers use different sampling approaches and data collection tools, and in addition to the variables of gender and tablet computer ownership, they investigate other factors such as smartphone or laptop ownership, purpose of usage for these, internet access and sufficiency in the techno-pedagogic field.

\section{REFERENCES}

[1] Aderinoye, R. A., Ojokheta, K. O., \& Olojede, A. A. (2007). Integrating mobile learning into nomadic education programmes in Nigeria: Issues and perspectives. The International Review of Research in Open and Distributed Learning, 8(2), 1-17

[2] Ağca, R. K., \& Bağc1, H. (2013). Students views of mobile tools usage in education. Journal of Research in Education and Teaching, 2(4), 295-302

[3] Alal1, I. K. (2015). Investigating university instructors' experiences and uses of mobile technology in teaching and learning in Saudi Arabia (Unpublished doctoral thesis). Graduate School of Wayne State University, Detroit, Michigan

[4] Al-Emran, M., Elsherif, H. M., \& Shaalan, K. (2016). Investigating attitudes towards the use of mobile learning in higher education. Computers in Human Behavior 56, 93-102. doi: 10.1016/j.chb.2015.11.033

[5] Al-Fahad, F. N. (2009). Students' attitudes and perceptions towards the effectiveness of mobile learning in King Saud University, Saudi Arabia. The Turkish Online Journal of Educational Technology, 8(2), 111-119.
[6] Alfarani, L. (2015). Influences on the adoption of mobile learning in Saudi women teachers in higher education. International Journal of Interactive Mobile Technologies, 9(2), 58-62.

[7] Altun, E., \& Ateş, A. (2014). Communication technologies. In Ö. Demirel, \& E. Altun (Eds.), Instructional technologies and material design (pp. 87-112). Ankara, Turkey: Pegem Akademi.

[8] Ary, D., Jacobs, L. C., \& Sorensen, C. (2010). Introduction to research in education (Eighth Edition). Wadsworth, USA: Cengage Learning.

[9] Aydemir, M., Küçük, S., \& Karaman, S. (2012). Examining students' views using tablet PC in distance education. Journal of Research in Education and Teaching, 1(4), 153-159.

[10] Bozkurt, A. (2015). Mobile learning is continuous learning experience at everywhere and every place. The Journal of Open University Applications and Investigations, 1(2), 65-81.

[11] Büyüköztürk, Ş., Çakmak, E. K., Akgün, Ö. E., Karadeniz, Ş., \& Demirel, F. (2016). Scientific research methods (22th edition). Ankara, Turkey: Pegem Akademi Publishing.

[12] Çavuş, N., \& Uzunboylu, H. (2009). Improving critical thinking skills in mobile learning. Procedia-Social and Behavioral Sciences, 1(2), 434-438.

[13] Çelik, A. (2013). M-learning attitude scale: Validity and reliability analyses. Journal of Research in Education and Teaching, 2(4), 172-185

[14] Çelik, A. (2012). The effect of square code assisted mobile learning environment on productive vocabulary learning in foreign language studies and student reviews: The example of mobile dictionary (Unpublished master's thesis). Gazi University, Institute of Educational Sciences, Ankara, Turkey.

[15] Chu, H. C. (2014). Potential negative effects of mobile learning on students' learning achievement and cognitive load-a format assessment perspective. Educational Technology \& Society, 17(1), 332-344.

[16] Colazzo, L., Molinari, A., Ronchetti, M., \& Trifonova, A. (2003). Towards a multi-vendor mobile learning management system. Proceedings for the World Conference on E-Learning. Phoenix, U.S.A.

[17] Çuhadar, C. (2014). Information technologies pre-service teachers' acceptance of tablet PCs as an innovative learning tool. Educational Sciences: Theory \& Practice, 14(2), 741-753.

[18] Dashti, F. A., \& Aldashti, A. A. (2015). EFL college students' attitudes towards mobile learning. International Education Studies, 8(8), 13-20

[19] Elçiçek, M., \& Bahçeci, F. (2015). The research of the vocational school student's attitudes towards mobile learning. Sakarya University, Journal of Education Faculty, 30, 16-33

[20] Eyyam, R., \& Yaratan, H. S. (2014). Impact of use of technology in mathematics lessons on student achievement and attitudes. Social Behavior and Personality, 42, 31-42. 
[21] Fabian, K., Topping, K. J., \& Barron, I. G. (2016). Mobile technology and mathematics: effects on students' attitudes, engagement, and achievement. Journal of Computers in Education, 3(1), 77-104. doi:10.1007/s40692-015-0048-8

[22] Festus, A.B., David, D., Orobosa, O.S., \& Olatunji, J. (2013). Attitude of primary school mathematics teachers towards the use of activity based learning methods in teaching mathematics in Nigerian schools. International Journal of Education Learning and Development, 1(1), $22-36$.

[23] Gray, D. E. (2004). Doing research in the real world. London: SAGE Publications.

[24] Gomez, S., Zervas, P., Sampson, D. G., \& Fabregat, R. (2014). Context-aware adaptive and personalized Mobile learning delivery supported by UoLmP. Journal of King Saud University-Computer and Information Sciences, 26(1), 47-61.

[25] Gündüz, Ş., \& Odabaşı, F. (2004). The importance of instructional Technologies and material development course at pre-service teacher education in information age. The Turkish Online Journal of Educational Technology, $3(1), 43-48$

[26] Güneș, F., Işık, A. D., \& Çukurbaş1, B. (2015). The effect of mobile learning applications using tablet computer skills of candidates teachers. Bartın University Journal of Faculty of Education, Special Issue on XIV. International Participation Symposium of Primary School Teacher Education, pp. 1-10. Bartın, Turkey. doi: 10.14686/BUEFAD.2015USOSOzelsayi13193

[27] Hosler, K. A. (2013). Pedagogies, perspectives, and practices: mobile learning through the experiences of faculty developers and instructional designers in centers for teaching and learning (Unpublished doctoral thesis). University of Northern Colorado, College of Education and Behavioral Sciences.

[28] Hwang, G.J., \& Chang, H.F. (2011). A formative assessment-based mobile learning approach to improving the learning attitudes and achievements of students. Computers \& Education, 56(4), 1023-1031.

[29] İlçi, A. (2014). Investigatıon of pre-service teachers' mobile learning readiness levels and mobile learning acceptance levels (Unpublished master's thesis). Middle East Technical University, Institute of Science, Ankara, Turkey.

[30] Jung, I. S. (2012). Asian learners' perception of quality in distance education and gender differences. International Review of Research in Open and Distance Learning, 13(2), $1-24$

[31] Kayış, A. (2005). Reliability analysis. In Ş. Kalaycı (Eds.), Multivariate statistical techniques with SPSS applied (pp. 404-409). Ankara, Turkey: Asil Publishing Distribution.

[32] Kemper, E., Stringfield. S., \& Teddlie, C. (2003). Mixed methods sampling strategies in social science research. In A. Tashakkori \& C. Teddlie (Eds.), Handbook of mixed methods in social \& behavioral research (pp. 273-296). Thousand Oaks, CA: Sage.

[33] Khaddage, F., \& Knezek, G. (2013). iLearn via mobile technology: A comparison of mobile learning attitudes among university students in two nations. In Advanced Learning Technologies (ICALT), 2013 IEEE 13th International Conference on Advanced Learning Technologies, pp. 256-258. doi:10.1109/ICALT.2013.79

[34] Kiger, D., Herro, D., \& Prunty, D. (2012). Examining the influence of a mobile learning intervention on third grade math achievement. Journal of Research on Technology in Education, 45(1), 61-82

[35] Kutluca, T., \& Ekici, G. (2010). Examining teacher candidates' attitudes and self-efficacy perceptions towards the computer assisted education. Hacettepe University Journal of Education, 38, 177-188.

[36] Kuşkonmaz, H. (2011). Determining teacher's perception of mobile learning at secondary schools (Unpublished master's thesis). Bahçeşehir University, Institute of Science, İstanbul, Turkey.

[37] Küle, G. (2012). Determining the students who educated marketing management lesson mobile learning perception (Unpublished master's thesis). Bahçeşehir University, Institute of Science, İstanbul, Turkey.

[38] Leung, C. H., \& Chan, Y. Y. (2003). Mobile learning: A new paradigm in electronic learning. In V. Devedzic, J. Spector, D. Sampson \& Kinshuk (Eds.), Proceedings of the 3rd IEEE Conference on Advanced Learning Technologies, (pp. 76-80).

[39] Liaw, S. S., \& Huang, H. M. (2015). How factors of personal attitudes and learning environments affect gender difference toward mobile distance learning acceptance. International Review of Research in Open and Distributed Learning, 16(4), 104-132

[40] Matias, A., \& Wolf, D. F. (2013). Engaging students in online courses through the use of mobile technology. Cutting-edge Technologies in Higher Education, 6, 115-142.

[41] Menzi, N., Önal, N., \& Çalışkan, E. (2012). Investigating educational researchers' views of using mobile technologies for educational purposes based on technology acceptance model. Ege Education Journal, 13(1), 40-55.

[42] Messinger, J. (2011). M-learning: An exploration of the attitudes and perceptions of high school students versus teachers regarding the current and future use of mobile devices for learning (Pepperdine University). ProQuest Dissertations and Theses, 227. Retrieved from http://seareh.proquest.eom/docview/914201229?accountid $=26967$

[43] Myers, R. Y. (2009). The effects of the use of technology in mathematics instruction on student achievement. FIU Electronic Theses and Dissertations, 136, Florida International University. Retrieved from http://digitalcommons.fiu.edu/etd/136

[44] NCTM. (2000). Principles and standards for school mathematics. Retrieved from https://www.nctm.org/

[45] Nute, N. E. (1997). The impact of engagement activity and manipulatives presentation on intermediate mathematics achievement, time-on-task, learning efficiency and attitude. ProQuest Dissertations and Theses. Retrieved from https://search.proquest.com/docview/304445573 
[46] Özgen, K., \& Bindak, R. (2011). The analyzing of the visibilities of high school students at the process of mathematical instructions. II. International Conference on New Trends in Education and Their Implications, 27-29 April, 2011, (pp.1007-1015), Antalya, Turkey.

[47] Park, Y. (2011). A pedagogical framework for mobile learning: Categorizing educational applications of mobile technologies into four types. International Review of Research in Open and Distance Learning, 12(2), 78-102.

[48] Park, S. Y., Nam, M. W., \& Cha, S. B. (2012). University students' behavioral intention to use mobile learning: Evaluating the technology acceptance model. British Journal of Educational Technology, 43(4), 592 - 605

[49] Rojano, T. (1996). The role of problems and problem solving in the development of algebra. In N. Bednarz, C. Kieran, \& L. Lee (Eds.), Approaches to algebra: Perspectives for research and teaching (pp. 137-145). Dordrecht, Netherlands: Kluwer Academic Publishers

[50] Rismark, M., Sølvberg, A. M., Strømme, A., \& Hokstad, L. M. (2007). Using mobile phones to prepare for university lectures: Student's experiences. The Turkish Online Journal of Educational Technology, 6(4), 85-89.

[51] Saran, M., Seferoglu, G., \& Çağıltay, K. (2009). Mobile assisted language learning: English pronunciation at learners' fingertips. Eurasian Journal of Educational Research, 34, 97-114

[52] Sharpless, M., Taylor, J., \& Vavoula, G. (2005). Towards a theory of mobile learning. In H. van der Merwe \& T. Brown (Eds.), Proceedings of m-Learn 2005. Retrieved from http://www.mlearn.org.za/CD/papers/Sharples-\%20Theory $\% 20$ of\%20Mobile.pdf

[53] Skillen, M.A. (2015). Mobile learning: Impacts on mathematics education. Proceedings of the 20th Asian Technology Conference in Mathematics, December 16-20, 2015, Leshan Vocational and Technical College, Leshan Normal University, Leshan, China. Retrieved from http://atcm.mathandtech.org/EP2015/full/3.pdf

[54] Solmaz, E., \& Gökçearslan, Ş. (2016). Mobile learning: A content analysis on thesis. ICITS 2016 Annual Symposium, 10 International Computers \& Instructional Technologies Symposium, Abstracts Book (pp. 78-79). Rize, Turkey.

${ }^{i}$ This manuscript was presented at the International Conference on Mathematics and Mathematics Education (ICMME-2017) as verbal statement, May 11-13, 2017 in Şanlıurfa / Turkey.
[55] [55] Sung, H. Y., Hwang, G. J., Liu, S. Y. \& Chiu, I. H. (2014). A prompt-based annotation approach to conducting mobile learning activities for architecture design courses. Computers \& Education, 76, 80-90.

[56] Tanriverdi, M. (2011). Development of a mobile learning application to support e-learning and analyze its effects (Unpublished master's thesis). Gazi University, Institute of Informatics, Ankara, Turkey.

[57] Tuzlak, K. (2016). Mobile learning opinions of the prospective teachers (Isparta Süleyman Demirel University Sampling). ICITS 2016 Annual Symposium, 10 International Computers \& Instructional Technologies Symposium, Abstracts Book (pp. 305-306), Rize, Turkey.

[58] Traxler, J. (2007). Defining, discussing and evaluating mobile learning: The moving finger writes and having writ... The International Review in Open and Distance Learning, 8(2), 1-13. doi: http://dx.doi.org/10.19173/irrodl.v8i2.346

[59] The Council of Higher Education. (1998). Education faculty teacher education degree programs. Ankara, Turkey. Retrieved from http://www.yok.gov.tr/

[60] Walker, K. (2007). Introduction: Mapping the landscape of mobile learning. In M. Sharples (Ed.), Big issue in mobile learning: a report of a new workshop by the Kaleidoscope Network of Excellence Mobile Learning Initiative (pp. 5-6), University of Nottingham, Learning Science and Research Institution, UK.

[61] Wiske, M. S., Franz, K. R., \& Breit, L. (2005). Teaching for understanding with technology. San Francisco, CA: Jossey-Bass.

[62] Wu, M. Y., Yu, P. Y., \& Weng, Y. C. (2012). A study on user behavior for I pass by UTAUT: Using Taiwan's MRT as an example. Asia Pacific Management Review, 17(1), 92-111.

[63] Yokuş, G. (2016). Education faculty undergraduate students' perceptions of mobile learning: A review and a mobile application development study towards educational sciences: Mobile Academy (Unpublished master's thesis). Mersin University, Institute of Educational Sciences, Mersin, Turkey. 